\title{
PACIENTŲ, SERGANČIŲ AKNE, GYVENIMO KOKYBĖS VERTINIMAS
}

\author{
Andrè Lideikaite் ${ }^{1}$, Anastasija Malevič ${ }^{1}$, Rūta Gancevičienè $\dot{\mathbf{e}}^{1,2}$ \\ ${ }^{I}$ Vilniaus universiteto Medicinos fakultetas, ${ }^{2}$ Vilniaus universiteto Medicinos fakulteto \\ Infekciniu, krütinès ligu, dermatovenerologijos ir alergologijos klinika
}

Raktažodžiai: aknè, dermatologinis gyvenimo kokybès indeksas, vertinimas, ittaka gyvenimo kokybei.

\section{Santrauka}

Aknè yra lètinè uždegiminė pilosebacinio (riebalu liaukos - plauko folikulo) vieneto odos liga. Daugelis studijų parodè, kad aknè turi didelès ịtakos pacientų savęs vertinimui, kasdieninei veiklai ir gyvenimo kokybei.

2015-2016 m. Vilniaus universiteto ligoninès Santaros klinikų (VUL SK) Dermatovenerologijos centre, keturiose Vilniaus miesto privačiose klinikose ir dviejuose kosmetologijos kabinetuose atliktas anoniminis anketinis tyrimas. Akne sergantys pacientai užpildè originalią anketą, kurioje pateikta 15 sudètinių klausimų ir Dermatologinio gyvenimo kokybės vertinimo klausimynas. Duomenys apdoroti Microsoft Exel programa, duomenų analizè atlikta SPSS ${ }^{\circledR}$ programa.

I tyrimą itraukti 262 respondentai, sergantieji akne, iš kurių 180 moteru (68,7 proc.) ir 82 vyrai (31,3 proc.). Vidutinis aknès pasireiškimo amžius tarp tiriamųju - 14,89 $( \pm 3,43)$ metai. Dermatologinio gyvenimo kokybės indekso anketos (DGKIA) balai išsidèste nuo 0 iki 28. DGKI bendras vidurkis $-8,96( \pm 5,72)$, moteru grupejje $-9,45( \pm 5,56)$, vyrų $-7,74( \pm 5,12)$, statistiškai reikšmingo skirtumo tarp lyčių nenustatyta $(\mathrm{p}=0,23)$. Reikšmingo statistinio skirtumo tarp amžiaus grupių taip pat nebuvo nustatyta $(\mathrm{p}=0,177)$. Dažniausiai aknès įtaka žmogaus gyvenimo kokybei buvo vidutinè (33,2 proc.). Rečiausiai aknè turèjo labai didelę ịtaką žmogaus gyvenimo kokybei $(3,8$ proc.). Daugiausia pacientų dẻl aknès jautèsi nusiminę, susigèdę, drovūs ar liūdni (19,7 proc.). Mažiausiai aknè trukdè seksualiniams santykiams $(5,27$ proc.).

Aknė dažniausiai pasireiškia jauniems vidutiniškai 21 metų amžiaus žmonèms. Dažniausiai aknè turèjo vidutinę įtaką žmogaus gyvenimo kokybei. Rečiausiai aknè turèjo labai didelę įtaką žmogaus gyvenimo ko- kybei. Dauguma pacientų dèl aknès jautèsi nusiminę, susigèdę, drovūs ar liūdni. Mažiausiai aknè trukdè seksualiniams santykiams.

\section{Ivadas}

Aknė yra lètinè uždegiminè riebalų liaukos - plauko folikulo odos liga, dažniausiai išryškejjanti veido, krūtinès ir nugaros viršutinès dalies srityse. Ši liga būdinga $9,4 \%$ visos populiacijos ir yra aštuntoje vietoje iš dažniausiai pasireiškiančių ligų visame pasaulyje [1,11]. Dažniausiai aknẻ būdinga ankstyvojo brendimo metu, kai androgeninès stimuliacijos įtakoje sukeliama per didelè riebalų gamyba, pakitusi folikulų keratinizacija, gramteigiamų bakterijų Propionibacterium acnes kolonizacija, uždegimo vystymasis ir pakitęs imuninis atsakas odoje [2, 21, 22].

Aknès klinikinès formos skiriamos priklausomai nuo dominuojančių išbėrimo elementų. Lengvesnèms aknès formoms būdingi neuždegiminiai išbèrimo elementai - komedonai. Sunkesnèms formoms - uždegiminiai išbèrimo elementai: mazgeliai, pūlinèliai, mazgai, cistos. Mazgai, cistos negydomos palieka įvairaus pobūdžio randus odoje [2].

Aknè nèra gyvybei pavojinga liga, tačiau ši liga gali stipriai paveikti socialinį, emocinị ir psichologinị asmens funkcionavimą [3]. Eilès tyrimų [6, 16-18, 20] rezultatai parodè, jog aknè siejama su padidèjusiu nerimu, depresijos simptomais, pykčio proveržiais ir ryškiu poveikiu pacientų gyvenimo kokybei $[3,5]$. Taip pat nustatyta, kad pacientai, sergantys akne, patiria sunkius psichosocialinius sutrikimus, kurie yra panašaus lygio kaip ir sergant sunkesnemis ligomis, tokiomis kaip bronchinè astma, epilepsija, cukrinis diabetas ar artritas. Tai rodo, kad būtina atsižvelgti i aknès poveiki paciento gyvenimo kokybei ir laiku suteikti reikiamą pagalbą [4, 19].

Pacientu gyvenimo kokybei vertinti yra sukurta daug ìvairių skalių ir klausimynų. DGKIA yra viena iš plačiausiai naudojamų klausimynų atliekant mokslinius tyrimus bei klinikinejje praktikoje. Tai yra klausimynas, sudarytas iš 10 trumpų klausimų, ir naudojama vertinti daugiau kaip 40 skirtingų odos ligų. DGKIA yra išversta į daugiau nei 
90 kalbų ir naudojamas daugiau nei 80 pasaulio šalių. DGKIA skirta naudoti pacientams, vyresniems nei 16 metų. Naudojant šį klausimyną, galima objektyviai ịvertinti, kaip kasdien jaučiasi akne sergantis pacientas, kokias gyvenimo sritis labiausiai paveikia ši liga, padeda pasirenkant efektyvesni gydymą bei naudojama gydymo veiksmingumui ivertinti. Taip pat labai naudinga nustatant didesnès rizikos pacientus, kuriuos liga ypač stipriai paveikia psichologiškai ir emociškai $[3,7,8,20]$.

Darbo tikslas: ịvertinti aknès poveikị ir jos daromą įtaką pacientų, sergančių akne, gyvenimo kokybei.

\section{Darbo metodika}

Tyrime dalyvavo vyresni nei 16 metų amžiaus 262 pacientai, sergantys akne. Tyrimas atliktas Vilniaus universiteto ligoninès Santaros klinikų Dermatovenerologijos centre, keturiose privačiose klinikose ir dviejuose kosmetologijos kabinetuose Vilniaus mieste 2015-2017 m. Atlikta anoniminé apklausa. Visi pacientai užpildè penkiolikos klausimų anketą ir Dermatologinio gyvenimo kokybès indekso klausimyną. Pirmają anketą sudare 6 bendrieji klausimai: paciento lytis, amžius, aknės pasireiškimo amžius, bėrimų elementai ir jų lokalizacija. Likusiais sudetiniais klausimais buvo siekiama išsiaiškinti pacientų kreipimosi ị skirtingus specialistus (dermatovenerologą, kosmetologą, šeimos gydytoją, vaistininką) ar gydymosi ypatumus namuose, taikytą gydymą, jo trukmę bei pacientų gydymo rezultatų ịvertinimą.

Aknès ligos sunkumas ịvertintas pagal klinikinę klasifikaciją, pasiūlytą Europos dermatologų forumo gairių (European Dermatology Forum guidelines), atsižvelgiant i ligos aktyvumą:

1) komedoninè forma;

2) lengva - vidutinio sunkumo papulopustulinè forma;

3) sunki papulopustulinè forma/ vidutinio sunkumo mazgelinè forma;

4) sunki mazgelinè forma/ konglobatinè forma.

Tyrimui atlikti naudotas DGKIA lietuvių kalba, kurị 1994 m. pateiké Finlay ir Khan [7]. Jị sudaro 10 trumpų klausimų, kuriais įvertinamos šios paciento gyvenimo sritys: fiziniai simptomai ir jausmai; kasdienė veikla; laisvalaikis; darbas / mokykla/ studijos; asmeniniai santykiai su draugais/ giminai-

1 lentelè. Galutinis Dermatologinio gyvenimo kokybės indekso vertinimas, atsižvelgiant ị balų sumą

\begin{tabular}{|l|l|}
\hline Balų suma & \multicolumn{1}{c|}{ Vertinimas } \\
\hline $0-1$ & nèra jokios įtakos paciento gyvenimo kokybei \\
\hline $2-5$ & nedidelè įtaka paciento gyvenimo kokybei \\
\hline $6-10$ & vidutinè ịtaka paciento gyvenimo kokybei \\
\hline $11-20$ & didelè ịtaka paciento gyvenimo kokybei \\
\hline $21-30$ & labai didele įtaka paciento gyvenimo kokybei \\
\hline
\end{tabular}

čiais/ partneriu ir gydymas. Kiekviename klausime vertinama aknès įtakos paciento gyvenimo kokybei stiprumas: „labai stipriai” ( 3 balai), „stipriai” ( 2 balai), ,šiek tiek” (1 balas) ir „visai ne” (0 balų), atsižvelgiant i problemas, su kuriomis susiduria pacientas per pastarają savaitę dèl savo odos būklès. Galutinis DGKI balas yra visų klausimų balų suma. Didžiausias balas, kuri galima surinkti, yra 30 balų. Kuo didesnis galutinis balas, tuo prastesne paciento gyvenimo kokybè (1 lentelè).

Duomenys buvo apdoroti naudojant Microsoft Excel programą, o duomenų statistinè analizė buvo atlikta naudojant SPSS ${ }^{\circledR}$ programinę įrangą. Skirtumai laikyti statistiškai reikšmingais, jei $\mathrm{p}<0,05$.

\section{Rezultatai}

I tyrimą įtraukti 262 respondentai, sergantieji akne, iš kurių 180 moteru ( 68,7 proc.) ir 82 vyrai ( 31,3 proc.). Vidutinis apklausoje dalyvavusiujų amžius $-20,91( \pm 5,63)$ metai, jauniausiems dalyvavusiems apklausoje buvo 16 metų, vyriausiam - 54 metai. Anksčiausiai aknẻ pasireiškė 9 metų, o vèliausiai - 30 metu (vidutinis aknès pasireiškimo amžius tarp tiriamujjų - 14,89 $( \pm 3,43)$ metai) (2 lentelè).

2 lentelè. Demografiniai pacientų duomenys

\begin{tabular}{|l|c|}
\hline Savybės & Dažnis \\
\hline Lytis & \\
\hline moterys & 180 \\
\hline vyrai & 82 \\
\hline Amžius (metais) & $20,91( \pm$ \\
\hline vidutinis & $5,63)$ \\
\hline jauniausias & 16 \\
\hline vyriausias & 54 \\
\hline $\begin{array}{l}\text { Aknės pasireiškimo amžius } \\
\text { (metais) }\end{array}$ \\
\hline vidutinis & \\
\hline anksčiausiai & $14,89( \pm 3,43)$ \\
\hline vėliausiai & 9 \\
\hline
\end{tabular}

3 lentelė. Aknès įtaka žmogaus gyvenimo kokybei

\begin{tabular}{|l|c|c|}
\hline $\begin{array}{l}\text { Aknės ịtaka gy- } \\
\text { venimo kokybei }\end{array}$ & Dažnis (n=) & Dažnis (\%) \\
\hline Neturi & 7 & 2,7 \\
\hline Nedidele & 77 & 29,4 \\
\hline Vidutine & 87 & 33,2 \\
\hline Didelė & 81 & 30,9 \\
\hline Labai didele & 10 & 3,8 \\
\hline Iš viso & 262 & 100,0 \\
\hline
\end{tabular}




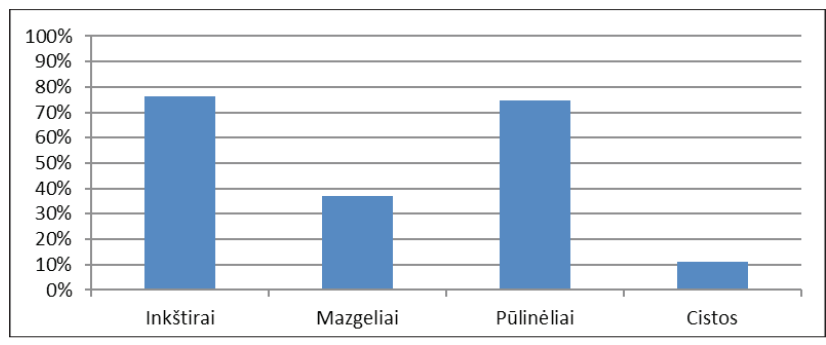

1 grafikas. Pažeidimų pobūdžio pasireiškimo dažnis

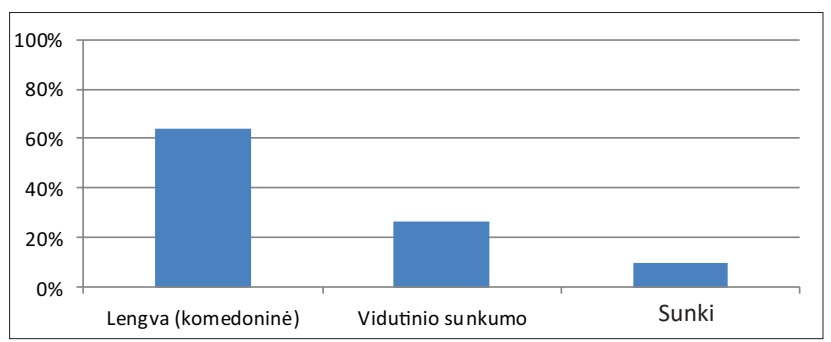

2 grafikas. Aknès formų pasireiškimo dažnis

Vyraujantis pažeidimų pobūdis buvo - inkštirai, kurie pasireiškè 76,3 proc. pacientų, rečiausiai pasitaike - cistos (11,1 proc.) (1 grafikas). Remiantis aknès sunkumo klasifikacija, dažniausiai pasireiškè lengva - komedoninè (63,7 proc.) aknès forma, rečiausiai - sunki mazgelinè - pūlinèlinè $(9,8$ proc.) (4 grafikas). Statistiškai reikšmingo skirtumo tarp lyčiu ir aknès pasireiškimo formos nebuvo nustatyta $(\mathrm{p}=0,078)$. Aknès išbèrimai dažniausiai lokalizavosi tik kaktoje (45,6 proc.) arba visame veide ( 45,2 proc.).

Dermatologinio gyvenimo kokybės indekso balai. Dermatologinio gyvenimo kokybès indekso (DGKI) anketos balai išsidèstè nuo 0 iki 28. DGKI bendras vidurkis $-8,96$ $( \pm 5,72)$, moterų grupeje $-9,45( \pm 5,56)$, vyru $-7,74( \pm$ $5,12)$, statistiškai reikšmingo skirtumo tarp lyčių nenustatyta $(\mathrm{p}=0,23)$. DGKI vidurkis įvairiose amžiaus grupèse buvo skirtingas, tačiau reikšmingo statistinio skirtumo tarp grupių nebuvo nustatyta $(\mathrm{p}=0,177)$.

Dermatologinio gyvenimo kokybės indekso interpretavimas. Remiantis DGKI balų išsidèstymu, aknè paveikè 255 (97,33 proc.) iš 262 pacientų gyvenimo kokybę. Dažniausiai aknès ittaka žmogaus gyvenimo kokybei buvo vidutinè $(33,2$ proc.). Rečiausiai aknè turèjo labai didelę ịtaka žmogaus gyvenimo kokybei (3,8 proc.) (3 lentelè). Aknè darè įtaką ivairiose žmogaus gyvenimo srityse. Daugiausia pacientų dèl aknės jautėsi nusiminę, susigèdę, drovūs ar liūdni $(19,75$ proc). Taip pat didelè dalis pacientų ( 15,02 proc.) skundèsi niežtinčia, skausminga, dilgčiojančia oda. Mažiausiai aknẻ trukdẻ seksualiniams santykiams $(5,27$ proc.), taip pat retai turejo ịtakos sportuojant (6,0 proc.) (3 grafikas).

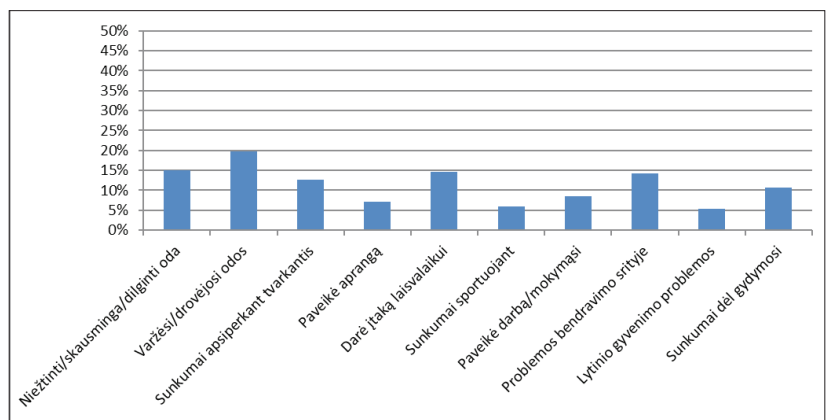

3 grafikas. Aknės įtaka įvairiose gyvenimo srityse

\section{Aptarimas}

Šiame tyrime dalyvavo 262 respondentai, sergantieji akne, iš kurių 180 moterų ( 68,7 proc.) ir 82 vyrai ( 31,3 proc.). Panaši tendencija stebima ir kituose tyrimuose - daugiau moterų nei vyrų yra ịtrauktų ị tiriamujų imtị $[8,13,14,20]$. Nors senesniuose epidemiologiniuose tyrimuose matoma tendencija, kad aknè dažniau pažeidžia vyriškos lyties pacientus. Taip pat jiems dažniau pasireiškia ir sunkesnès aknès formos [10]. Tačiau moterys labiau linkusios rūpintis savo sveikata ir dažniau kreipiasi ị gydytojus [9]. Vyrai linkę kreiptis ị gydytojus tik tada, kai pasireiškia sunkesni ligos simptomai. Tai galètų paaiškinti, kodèl tiek mūsų tyrime, tiek ir kituose atliktuose tyrimuose, didesnę dali imties sudaro moterys.

Vidutinis apklausoje dalyvavusiųų amžius $-20,91$ ( \pm $5,63)$ metai, jauniausi dalyvaujantys pacientai buvo 16 metu amžiaus, o vyriausias - 54 metų. Anksčiausiai aknè pasireišké 9 metų pacientams, o vèliausiai - 30 metų (vidutinis aknès pasireiškimo amžius tarp tiriamujų - $14,89( \pm 3,43)$ metai). Dažniausiai liga prasideda paauglystès laikotarpiu. Lytinio brendimo metu suaktyvejja riebalinių liaukų veikla, padidejja riebalu gamyba [11]. Šie riebalinių liaukų pokyčiai yra vienas iš aknès patogenezès faktorių.

Vyraujantis pažeidimų pobūdis buvo - inkštirai, kurie pasireiškè 76,3 proc. pacientu, rečiausiai pasitaike - cistos $(11,1 \%)$. Remiantis aknès sunkumo klasifikacija, dažniausiai pasireiškè lengva - komedoninè (63,7 proc.) aknès forma, rečiausiai - sunki mazgelinè - pūlinèlinè ( 9,8 proc.). Aknès išbėrimai dažniausiai lokalizavosi tik kaktoje (45,6 proc.) arba visame veide ( 45,2 proc.). Remiantis ankstesniais atliktais tyrimais stebima panaši tendencija, kad dažniausiai aknè pasireiškej lengva forma ir dažniausiai lokalizavosi veido srityje $[12,13]$. Aknè dažniausiai pažeidžia veido sriti, kuriose gausu riebalinių liaukų.

Šio tyrimo rezultatai rodo tiesioginę aknès įtaką pacientų gyvenimo kokybei. Aknès daromos įtakos gyvenimo kokybei stiprumas tarp pacientų pasiskirstė taip: nedidelè itaka 29,4\%, vidutine - 33,2 proc., didele - 30,9 proc. ir labai didele - 3,8 proc. Panašūs rezultatai gauti ir $2017 \mathrm{~m}$. 
Lietuvoje atliktame kitame tyrime, kuriame tirta taip pat pacientų, sergančių akne, gyvenimo kokybè. Šio tyrimo rezultatai parodè, jog aknè nedidelę ịtaką turèjo 14,1\% pacientų, vidutinę $-30,2$ proc., didelę $-45,1$ proc. ir labai didelę $-7,1$ proc. pacientų [20].

Rezultatų skirtumus galèjo lemti tai, jog ị mūsų tyrimą buvo įtraukti pacientai, besigydantys tiek pas kosmetologus, tiek pas gydytojus dermatovenerologus. Todèl daugumai pacientų buvo nustatyta lengva aknès forma. O kitame tyrime visų pacientų aknès sunkumo laipsnị turèjo įvertinti dermatovenerologas, todèl ị šią studiją buvo įtraukti pacientai su sunkesnemis aknès formomis (daugumai pacientų nustatyta vidutinio sunkumo aknès forma - 36,9\%) [20].

DGKI balų bendras vidurkis buvo 8,96, tuo tarpu panašiuose tyrimuose, atliktuose kitose šalyse, rezultatai yra skirtingi. Irane H. Safizadeh atliktoje studijoje, kurioje dalyvavo 220 pacientu, vidutinis DGKI balas buvo $6,42( \pm 4,77)$, Pietų Indijoje $-6,91( \pm 5,74)$, Graikijoje - 4,02 [8,9,18]. Pacientu gyvenimo kokybė buvo geresnè minètuose tyrimuose, palyginti su šiuo tyrimu. Rezultatų skirtumų viena iš priežasčių gali būti tyrimo atrankos kriterijai. Mes tyrème pacientus, kurie lankèsi ne tik pas gydytoją dermatovenerologą, bet ir pas kosmetologą. Galima daryti prielaidą, kad pacientai, kurie lankėsi pas kosmetologą, negavo kvalifikuotos ir jiems tinkamos pagalbos ir dèl to galèjo būti mažiau patenkinti savo odos būkle bei gyvenimo kokybe. Kita vertus, Egipte vykusio Abdel-Hafez tyrimo metu DGKI balų vidurkis buvo 11,9 moteru grupeje ir atitinkamai 15,0 vyrų grupejje, o tai yra blogesnis rezultatas nei gautas mūsų tyrimo metu [10]. Šie skirtumai gali būti susiję su ligos šalių kultūriniais skirtumais, aknės sunkumo laipsnio, taip pat su skirtingais pacientų lūkesčiais.

\section{Išvados}

1. Aknè dažniausiai pasireiškia jauniems, vidutiniškai 20,91 metų amžiaus žmonèms.

2. Aknè dažniausiai pasireiškè lengva forma.

3. Dažniausia aknès lokalizacija - veido sritis.

4. Dažniausiai aknè turèjo vidutinę įtaka žmogaus gyvenimo kokybei.

5. Rečiausiai aknė turèjo labai didelę ịtaka žmogaus gyvenimo kokybei.

6. Dauguma pacientų dèl aknès jautèsi nusiminę, susigèdę, drovūs ar liūdni.

7. Mažiausiai aknè trukdè seksualiniams santykiams.

\section{Literatūra}

1. Darren D Lynn, Tamara Umari. et al. The epidemiology of acne vulgaris in late adolescence. dolesc Health Med Ther 2016; 7 : $13-25$.
https://doi.org/10.2147/AHMT.S55832

2. http://apps.who.int/medicinedocs/en/d/Jh2918e/20. html\#Jh2918e.20 (paskutinị kartą žiūrèta 2017-12-02)

3. Tasoula E, Gregoriou S. et al. The impact of acne vulgaris on quality of life and psychic health in young adolescents in Greece. Results of a population survey. An Bras Dermatol 2012 Nov-Dec; 87(6): 862-869.

https://doi.org/10.1590/S0365-05962012000600007

4. Shuster S, Fisher GH, Harris E, Binnell D. The effect of skin disease on self image [proceedings] Br J Dermatol 1978;99(Suppl 16):18-9.

https://doi.org/10.1111/j.1365-2133.1978.tb15214.x

5. Aktan S, Ozmen E, Sanli B. Anxiety, depression, and nature of acne vulgaris in adolescents. Int J Dermatol 2000 May; 39(5):354-7.

https://doi.org/10.1046/j.1365-4362.2000.00907.x

6. Hazarika N and Rajaprabha R. Assessment of Life Quality Index among patients with acne vulgaris in a suburban population. Indian J Dermatol 2016 Mar-Apr; 61(2): 163-168.

https://doi.org/10.4103/0019-5154.177758

7. Finlay AY, Khan GK. Dermatology Life Quality Index (DLQI) - a simple practical measure for routine clinical use. Clin Exp Dermatol 1994 May; 19(3):210-6.

https://doi.org/10.1111/j.1365-2230.1994.tb01167.x

8. Vilar GN. et al. Quality of life, self-esteem and psychosocial factors in adolescents with acne vulgaris. An Bras Dermatol 2015; 90(5):622-9.

https://doi.org/10.1590/abd1806-4841.201533726

9. Bertakis KD. et al. Gender differences in the utilization of health care services. J Fam Pract 2000 Feb; 49(2):147-52.

10. Tan JKL and Bhate K. A global perspective on the epidemiology of acne. Br J Dermatol 2015 Jul; 172 Suppl 1:3-12.

https://doi.org/10.1111/bjd.13462

11. Li X, He C. et al. A review of the role of sebum in the mechanism of acne pathogenesis. J Cosmet Dermatol 2017 May 29. doi: $10.1111 /$ jocd. 12345 .

https://doi.org/10.1111/jocd.12345

12. Priya Cinna P, Durai T and Dhanya G Nair. Acne vulgaris and quality of life among young adults in South India. Indian J Dermatol 2015 Jan-Feb; 60(1).

13. Ghaderi R, Saadatjoo A and Ghaderi F. Evaluating of life quality in patients with acne vulgaris using generic and specific questionnaires. Dermatol Res Pract 2013; 2013: 108624.

https://doi.org/10.1155/2013/108624

14. Safizadeh H, Shamsi-Meymandy S and Naeimi A. Quality of life in iranian patients with acne. Dermatol Res Pract 2012; 2012: 571516.

https://doi.org/10.1155/2012/571516

15. Hazarika N and Rajaprabha RK. Assessment of life quality index among patients with acne vulgaris in a suburban population. Indian J Dermatol 2016 Mar-Apr; 61(2): 163-168. 
https://doi.org/10.4103/0019-5154.177758

16. Tejada Cdos S, Mendoza-Sassi RA, Almeida HL, Figueiredo PN, Tejada VF. Impact on the quality of life of dermatological patients in southern Brazil. An Bras Dermatol 2011; 86:1113-21.

https://doi.org/10.1590/S0365-05962011000600008

17. Hanisah A, Omar K, Shah SA. Prevalence of acne and its impact on the quality of life in school-aged adolescents in Malaysia. J Prim Health Care 2009; 1:20-5.19.

18. Tasoula E, Gregoriou S, Chalikias J, Lazarou D, Danopoulou I, Katsambas A. et al. The impact of acne vulgaris on quality of life and psychic health in young adolescents in Greece. Results of a population survey. An Bras Dermatol 2012; 87:862-9. https://doi.org/10.1590/S0365-05962012000600007

19. Aktan S, Ozmen E, Sanli B. Anxiety, depression, and nature of acne vulgaris in adolescents. Int J Dermatol 2000;39:354-7. https://doi.org/10.1046/j.1365-4362.2000.00907.x

20. Lukaviciute L., Navickas P., Navickas A., Grigaitiene J., Ganceviciene R., Zouboulis CC. Quality of life, anxiety prevalence, depression symptomatology and suicidal ideation among acne patients in Lithuania. J Eur Acad Dermatol Venereol 2017 Jul 14. https://doi.org/10.1111/jdv.14477

21. Moradi Tuchayi S, Makrantonaki E, Ganceviciene R, Dessinioti C, Steven R. Feldman \& Christos, Zouboulis C. Acne vulgaris. Nature Reviews Disease Primers 1. 15029 (2015), doi:10.1038/ nrdp.2015.29.

https://doi.org/10.1038/nrdp.2015.29

22. Jahns AC, Eilers H, Ganceviciene R, Alexeyev OA. Propionibacterium species and follicular keratinocyte activation in acneic and normal skin. Br J Dermatol 2015 Apr; 172(4):981-7. doi: 10.1111/bjd.13436. Epub 2014 Dec 11.

https://doi.org/10.1111/bjd.13436

23. Nast A, Dreno B, Bettoli V. et al. European evidence-based (S3) guidelines for the treatment of acne. J Eur Acad Dermatol Venereol 2012; 26(suppl 1): 1-29.

https://doi.org/10.1111/j.1468-3083.2011.04374.x

\section{EVALUATION OF QUALITY OF LIFE IN PATIENS WITH ACNE}

\section{A. Lideikaitė, A. Malevič, R. Gancevičienė}

Key words: acne, dermatology life quality index, evaluation, influence on quality of life.
Summary

Introduction. Acne vulgaris is a chronic inflammatory skin disease of pilosebaceous (sebaceous gland - hair follicles) unit. Lots of studies have revealed that it has significant effect on patient's self-image, daily activity and their quality of life.

Aim. The purpose of this research was to investigate the health-related quality of life in patients with acne vulgaris.

Materials and methods. This study was carried out on patients with acne vulgaris. An anonymous survey conducted in 2015-2016 at the Vilnius University Hospital Santaros clinics Centre of Dermatovenerology, four private clinics and two cosmetology cabinets in Vilnius city. All patients filled out fifteen composite questions form and Dermatology Life Quality Index (DLQI) questionnaire. Data were processed using Microsoft Excel, data statistical analysis was conducted by using SPSS $®$ software.

Results. 262 respondents with acne were involved in the study: 180 female $(68.7 \%)$ and 82 male $(31.3 \%)$. Average participant's age when acne manifested - 14-15 yrs. The DLQI scores ranged from 0 to 28 . The general mean of DLQI score was $8,96( \pm 5,72)$. The mean scores of DLQI in male was 7,74 $( \pm 5,12)$ and female was $9,45( \pm 5,56)$ which was not statistically significant $(P=0.23)$. The mean score of DLQI in different age groups had not a statistically significant difference $(\mathrm{p}=0.177)$. The most common impact of acne vulgaris on quality of life was moderate $(33,2 \%)$ and the rarest - extremely large $(3,8 \%)$. The majority of patients were embarrassed or self conscious because of acne $(19,75 \%)$ and the least acne caused sexual difficulties in patient's life $(5,27 \%)$.

Conclusion. The acne is most commonly seen in young people on average 20.91 years. In most cases of the investigation acne had moderate effect on patient's life. In rare cases the impact of acne on quality of life was extremely large. The majority of patients were embarrassed or self conscious because of acne, the least acne impacted patient's sexual life.

Correspondence to: andrelideikaite@gmail.com

Gauta 2017-12-07 